Article

\title{
Dynamics of Photogenerated Charge Carriers in $\mathrm{TiO}_{2} / \mathrm{MoO}_{3}, \mathrm{TiO}_{2} / \mathrm{WO}_{3}$ and $\mathrm{TiO}_{2} / \mathrm{V}_{2} \mathrm{O}_{5}$ Photocatalysts with Mosaic Structure
}

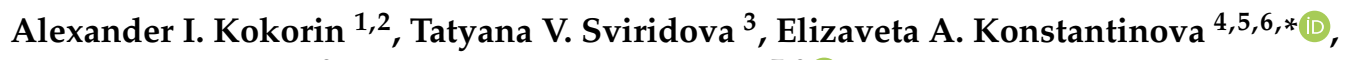 \\ Dmitry V. Sviridov ${ }^{3}$ and Detlef W. Bahnemann ${ }^{7,8} \mathbb{D}$ \\ 1 N.N. Semenov Federal Research Center for Chemical Physics RAS, 119991 Moscow, Russia; \\ alex-kokorin@yandex.ru \\ 2 Department of Technology, Plekhanov Russian University of Economics, 119991 Moscow, Russia \\ 3 Chemical Department, Belarusian State University, 220030 Minsk, Belarus; sviridova@bsu.by (T.V.S.); \\ sviridov@bsu.by (D.V.S.) \\ 4 Physics Department, Lomonosov Moscow State University, 119991 Moscow, Russia \\ 5 National Research Center "Kurchatov Institute", 123182 Moscow, Russia \\ 6 Faculty of Nano-, Bio-, Information and Cognitive Technologies, Moscow Institute of Physics and \\ Technology, 141700 Dolgoprudny, Russia \\ 7 Laboratory "Photoactive Nanocomposite Materials", Saint-Petersburg State University, \\ 198504 Saint-Petersburg, Russia; bahnemann@iftc.uni-hannover.de \\ 8 Institut für Technische Chemie, Leibniz Universität Hannover, D-30167 Hannover, Germany \\ * Correspondence: liza35@mail.ru; Tel.: +7-916-887-49-14
}

Received: 9 August 2020; Accepted: 1 September 2020; Published: 4 September 2020

check for updates

\begin{abstract}
Titania is a widely used photocatalytic material possessing such advantages as low cost and high reactivity under the ultraviolet light illumination. However, the fast recombination of photoexcited charge carriers limits its application. Herein, we have synthesized original nanomaterials with mosaic structures that exhibited well-defined heterojunctions and new properties. Using SEM, XRD, EPR spectroscopy, photocatalytic measurements, and photoinduced pathphysiological activity of these photocatalysts, we studied the processes of charge carrier accumulation in $\mathrm{TiO}_{2} / \mathrm{MoO}_{3}$, $\mathrm{TiO}_{2} / \mathrm{WO}_{3}$, and $\mathrm{TiO}_{2} / \mathrm{V}_{2} \mathrm{O}_{5}$ under in situ UV illumination with emphasis on the charge exchange between energy levels of these nanosized semiconductors. It is shown that the accumulation of photoinduced charges occurs in two forms (i) filled electron traps corresponding to $\mathrm{Ti}^{4+} / \mathrm{Ti}^{3+}$ levels and (ii) $\mathrm{Mo}^{5+}$ centers, both forms contributing to the photoinduced biocide activity of the samples. This work demonstrates that light exposure of heterostructure photocatalysts with mosaic surfaces produces different types of charge-trapping centers capable of interacting with molecular oxygen yielding peroxo species, which provide long-life light-induced "self-cleaning" behavior. Such photoaccumulating materials open new opportunities in developing light-driven self-sterilization structures exhibiting a prolonged bactericidal effect up to $10 \mathrm{~h}$ after stopping light exposure.
\end{abstract}

Keywords: nanomaterials; heterostructure photocatalysts; oxide semiconductors; charge accumulation; paramagnetic centers; light-induced photoactivity

\section{Introduction}

Numerous photocatalysts have been synthesized and tested during the last 30 years, e.g., [1-9] and references therein. The combination of titania as a highly active semiconductor catalyst [5] with redox-active oxides [10,11], hydroxides [12] and polyoxometallates [13] enables the accumulation of photoinduced charge carriers which can be then spent in bacteria killing processes under dark 
conditions as well as for the degradation of toxic organic chemicals. However, the photoaccumulating catalysts of this type demonstrate rather low charge storage capacity that constrain the prospects of their application for developing the photobiocide materials with prolonged antimicrobial activity. The real breakthrough in developing a charge storage photocatalyst was achieved recently when the metastable phase of $\mathrm{MoO}_{3}, \mathrm{WO}_{3}$, and $\mathrm{V}_{2} \mathrm{O}_{5}$ with open channel structures was used together with $\mathrm{TiO}_{2}$ yielding thin-film heterostructure photocatalysts capable of retaining microbiocide activity for a unprecedentedly long time (up to $10 \mathrm{~h}$ ) after exposure [14-18].

The idea of a systematic study of metal ion doping in nanosized $\mathrm{TiO}_{2}$ particles has already been discussed in [19]. The photoreactivities and the transient charge carrier recombination dynamics in $\mathrm{Fe}^{3+}, \mathrm{Mo}^{5+}, \mathrm{Ru}^{3+}, \mathrm{Os}^{3+}, \mathrm{Re}^{5+}, \mathrm{V}^{4+}$, and the $\mathrm{Rh}^{3+}$ doped $\mathrm{TiO}_{2}$ crystalline matrix were measured and significantly influenced photoreactivity, charge carrier recombination rates, and interfacial electron-transfer rates [19]. The conduction band electron reduction in an electron acceptor $\left(\mathrm{CCl}_{4}\right.$ dechlorination) and the valence band hole oxidation of an electron donor $\left(\mathrm{CHCl}_{3}\right.$ degradation) were studied in detail. Doping with ions shown above at $0.1-0.5 \%$ increased the photoactivity for both redox reactions, while $\mathrm{Co}^{3+}$ and $\mathrm{Al}^{3+}$ doping decreased the photoactivity. It was revealed that transient absorption signals upon laser flash photolysis $\left(\lambda_{\mathrm{ex}}=355 \mathrm{~nm}\right)$ at $\lambda=600 \mathrm{~nm}$ were extended up to $50 \mathrm{~ms}$ for $\mathrm{Fe}^{3+}-, \mathrm{V}^{4+}-, \mathrm{Mo}^{5+}$, , and $\mathrm{Ru}^{3+}$-doped $\mathrm{TiO}_{2}$, and the undoped nano- $\mathrm{TiO}_{2}$ showed a complete "blue electron" signal decay within $200 \mu \mathrm{s}$. $\mathrm{Co}^{3+}$ - and $\mathrm{Al}^{3+}$-doped $\mathrm{TiO}_{2}$ were characterized by rapid signal decays with a complete loss of absorption signals within $5 \mu \mathrm{s}$. Photoactivities increased with the concentration of trapped charge carriers and the authors concluded the complex function effecting of the dopant concentration, the energy level of dopants within the $\mathrm{TiO}_{2}$ lattice, their electronic states, the electron donor concentration and distribution, and the light intensity on the rate of the process and its mechanism [19].

The photoinduced redox transformations responsible for charge storage in these photocatalytic systems are based on the light-induced charge carrier separation using composites of two and three different metal oxides, which are accompanied by the generation of paramagnetic centers that makes the electron paramagnetic resonance (EPR) spectroscopy a powerful tool for the investigation of the mechanism of such processes, as well as the features of photoaccumulation effects. Experimental results quantitatively described changes in EPR spectra; dynamics of the processes occurred in $\mathrm{N}-, \mathrm{Ti}^{3+}$-, $\mathrm{Mo}^{5+}$-, and $\mathrm{V}^{4+}$-doped $\mathrm{TiO}_{2}$ (anatase); and their most probable mechanisms were recently discussed in detail in [15-18].

Similar independent results based on the EPR method in the investigation of phenomena occurring in heterogeneous photocatalysis, the stabilization of the carriers, and their consequent surface reactivity was also recently published in [20]. The authors described the behavior of four photoactive oxides $\left(\mathrm{ZrO}_{2}, \mathrm{ZrTiO}_{4}, \mathrm{TiO}_{2}\right.$, and $\left.\mathrm{ZnO}\right)$ with different band gaps which exhibited electron and hole stabilization. The EPR technique revealed the following stabilized centers: $\mathrm{Zr}^{4+}, \mathrm{Ti}^{4+}$, and $\mathrm{Zn}^{2+}$ for trapped electrons and the hole trapping such as the formation of $\mathrm{O}^{-}$centers [20]. The electron transfer reactivity at the surface of the photogenerated carriers was monitored using specific scavengers in the gas phase over the solid (molecular $\mathrm{O}_{2}$ and $\mathrm{H}_{2}$ ) for electron scavenging and hole scavenging, respectively. EPR was particularly useful for checking the features of novel photocatalytic materials [20].

In this paper, we used the SEM, XRD, EPR spectroscopy, photocatalytic measurements, and photoinduced pathphysiological activity of photocatalysts to elucidate the structure of energy levels involved in the storage of the reductive energy in $\mathrm{TiO}_{2} / \mathrm{MoO}_{3}\left(\mathrm{WO}_{3}, \mathrm{~V}_{2} \mathrm{O}_{5}\right)$ heterostructure photocatalysts under in situ UV light illumination with emphasis on the charge exchange between these levels of different nanosized oxide semiconductors. 


\section{Results and Discussion}

\subsection{Characterization of the Samples}

\subsubsection{Microscopy}

All materials used in the work were purchased from Sigma-Aldrich Chemical Co. and used as supplied. For preparation of solutions, the Milli-Q water was used. The thin-film photocatalysts were prepared using aqueous dispersions of $\mathrm{TiO}_{2}, \mathrm{MoO}_{3}, \mathrm{WO}_{3}$, and $\mathrm{V}_{2} \mathrm{O}_{5}$ contrastingly to hydrolytically, pyrolytically, or mechanochemically derived $\mathrm{TiO}_{2} / \mathrm{MoO}_{3}\left(\mathrm{~V}_{2} \mathrm{O}_{5}, \mathrm{~V}_{2} \mathrm{O}_{5}: \mathrm{MoO}_{3}\right)$ composite photocatalysts investigated in our previous works [14-18,21]. These photocatalysts consisting of the initially synthesized crystallites exhibited well-defined heterojunctions and demonstrated a mosaic structure. The detailed mechanism behind solvothermal synthesis based on the polycondensation of oxo-compounds is discussed elsewhere [14,21]. This synthetic procedure yields perfect crystallites of hexagonal $\mathrm{MoO}_{3}$, hexagonal $\mathrm{WO}_{3}$, and $\mathrm{V}_{2} \mathrm{O}_{5}$ xerogel (both crystalline polymorphs possess the lamellar structure) with the medium size of 200-500 $\mathrm{nm}$.

The morphological investigations employing SEM provided evidence about mosaic structure (Figure 1).
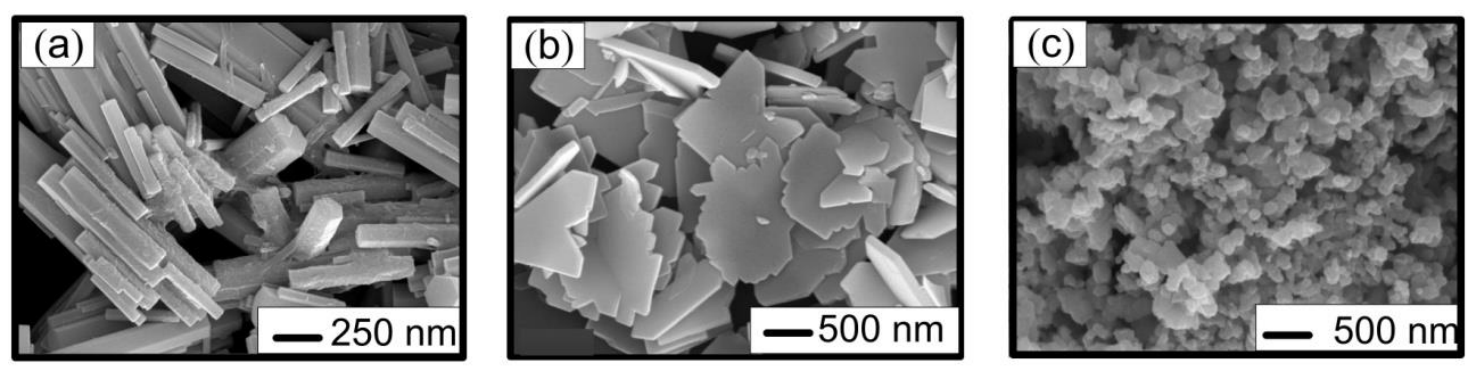

Figure 1. SEM images of submicron-sized crystallites of (a) $h-\mathrm{MoO}_{3},(\mathbf{b}) h-\mathrm{WO}_{3}$, and (c) $\mathrm{V}_{2} \mathrm{O}_{5}$ xerogel used for preparation of heterostructure photocatalysts.

The AFM (atomic force microscope) images for $\mathrm{TiO}_{2} / \mathrm{MoO}_{3}, \mathrm{TiO}_{2} / \mathrm{WO}_{3}$, and $\mathrm{TiO}_{2} / \mathrm{V}_{2} \mathrm{O}_{5}$ heterostructure photocatalysts given in Figure 2 show that the size of building blocks forming the surface of composite film exhibited a considerable decrease when going from $\mathrm{TiO}_{2} / \mathrm{MoO}_{3}$ film to $\mathrm{TiO}_{2} / \mathrm{WO}_{3}$ film and then to $\mathrm{TiO}_{2} / \mathrm{V}_{2} \mathrm{O}_{5}$ (the mean roughness evaluated from AFM $10 \times 10 \mu \mathrm{m}$ plots decreased from $398 \mathrm{~nm}$ to 380 and $306 \mathrm{~nm}$, correspondingly).

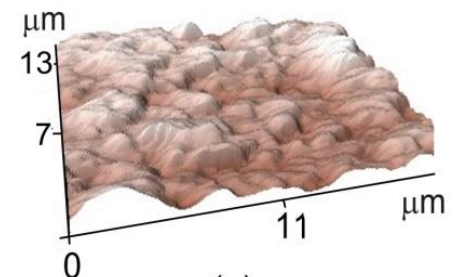

(a)

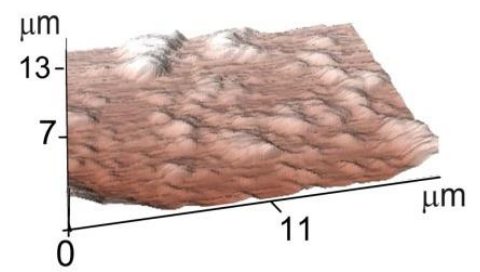

(b)

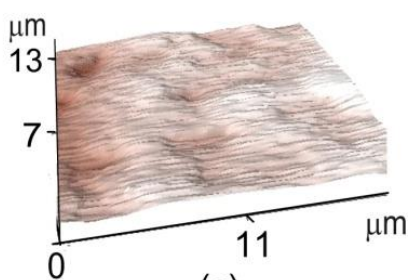

(c)

Figure 2. AFM surface plots for (a) $\mathrm{TiO}_{2}-\mathrm{MoO}_{3}$, (b) $\mathrm{TiO}_{2}-\mathrm{WO}_{3}$, and (c) $\mathrm{TiO}_{2}-\mathrm{V}_{2} \mathrm{O}_{5}$.

The observed decrease in the composite roughness can be attributed to the well-known fact of a mutual protective action of composite-forming oxide components against their crystallization that hampers rearrangements in the composite film during an annealing and a strong tendency to form aggregates inherent in $\mathrm{V}_{2} \mathrm{O}_{5}$ particles. Notwithstanding these variations in the surface roughness that should considerably affect the specific contact angle values, the heterogeneous binary surface of composite films remained hydrophilic (the water contact angle amounted to $\sim 25^{\circ}$ even for $\mathrm{TiO}_{2} / \mathrm{V}_{2} \mathrm{O}_{5}$ 
film with the smoothest surface) that should facilitate water adsorption from humid air and thus creates favorable conditions for photocatalyst operation.

\subsubsection{XRD}

According to XRD analysis, hexagonal $\mathrm{MoO}_{3}$ with an admixture of monoclinic $\mathrm{MoO}_{3} \cdot \mathrm{H}_{2} \mathrm{O}$, hexagonal $\mathrm{WO}_{3}$ with an admixture of orthorhombic $\mathrm{WO}_{3} \cdot 0.33 \mathrm{H}_{2} \mathrm{O}$, and lamellar $\mathrm{V}_{2} \mathrm{O}_{5}$ xerogel crystallites were formed (Figure 3).

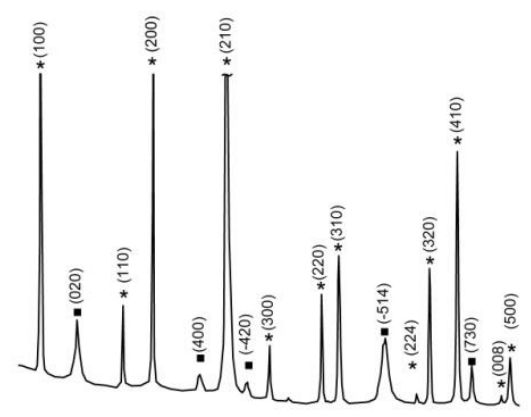

(a)
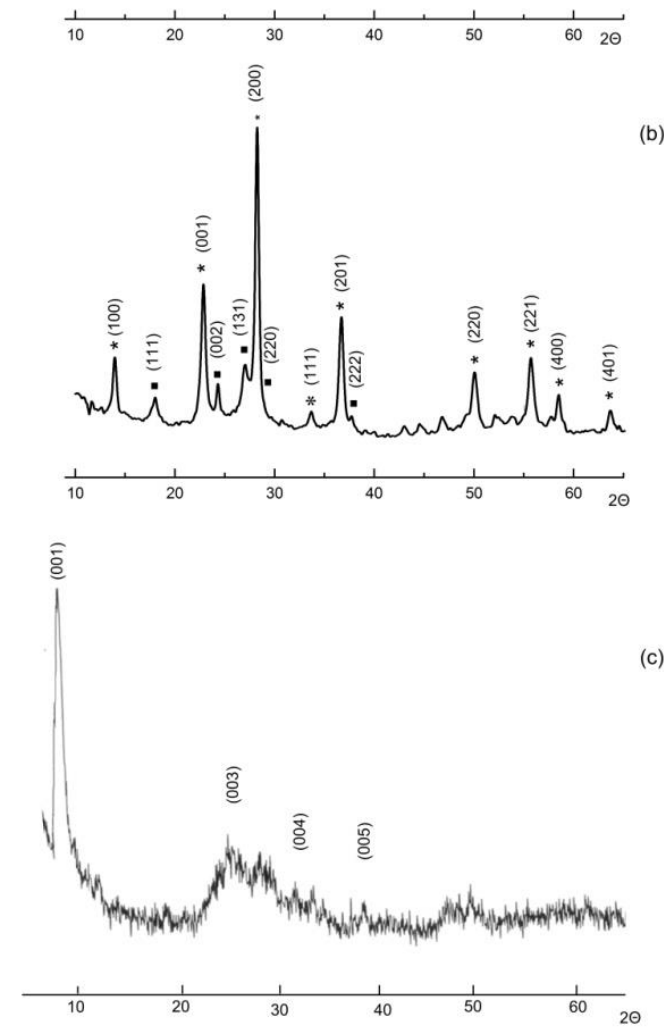

Figure 3. XRD patterns of (a) $h-\mathrm{MoO}_{3},(\mathbf{b}) h-\mathrm{WO}_{3}$, and (c) monoclinic $\mathrm{V}_{2} \mathrm{O}_{5}$ xerogel crystallites used for preparation of heterostructure photocatalysts. Hexagonal $\mathrm{MoO}_{3}$ and $\mathrm{WO}_{3}$ (marked at the pattern with asterisks) contain an admixture of monoclinic $\mathrm{MoO}_{3} \cdot \mathrm{H}_{2} \mathrm{O}$ and orthorhombic $\mathrm{WO}_{3} \cdot 0.33 \mathrm{H}_{2} \mathrm{O}$ (marked with squares). $\theta$ is the diffraction angle.

According to XRD analysis, the resultant titania was anatase (Figure 4) with the medium size of crystallites of ca. $4 \mathrm{~nm}$. The size of crystallites (regions of coherent scattering) was estimated from the broadening of diffraction reflections using the Scherer formula:

$$
d_{X R D}=\frac{k \lambda}{\beta \cos \theta}
$$


where $d_{X R D}$ is the average size of the coherent scattering region, $\beta$ is the width of the corresponding diffraction peak at half maximum, $\lambda$ is the wavelength of the radiation used, $\theta$ is the diffraction angle, and $k=0.9$.

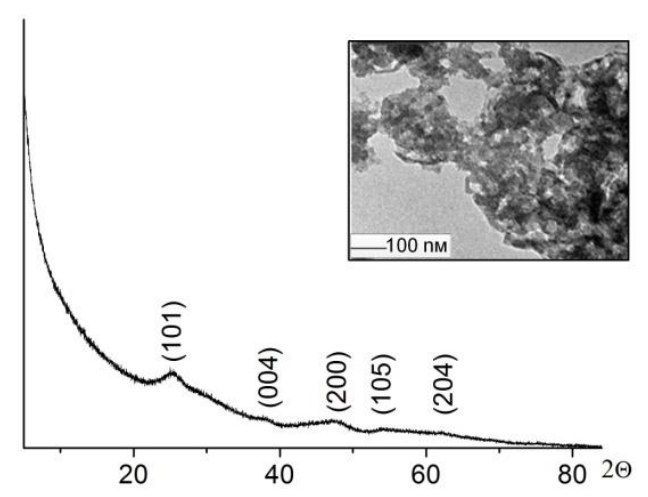

Figure 4. XRD pattern and TEM image of $\mathrm{TiO}_{2}$ nanophase used for preparation of heterostructure photocatalysts.

The mixtures of $\mathrm{TiO}_{2}$ sol and $\mathrm{MoO}_{3}\left(\mathrm{~V}_{2} \mathrm{O}_{5}\right)$ suspensions (2:1 in the case of $\mathrm{TiO}_{2} / \mathrm{MoO}_{3}$ and $\mathrm{TiO}_{2} / \mathrm{V}_{2} \mathrm{O}_{5}$ photocatalysts) were deposited onto the glass substrate by pulverization. The resultant coating was then annealed at $400{ }^{\circ} \mathrm{C}$. The XRD analysis evidenced that the annealing did not result in the recrystallization of the oxide phases forming the photocatalytic film. According to the AFM measurements thus obtained, thin-film photocatalytic coatings had a thickness of ca. $2.5 \mu \mathrm{m}$.

\subsection{Photocatalytic and Pathphysiological Activity of $\mathrm{TiO}_{2} / \mathrm{MoO}_{3}, \mathrm{TiO}_{2} / \mathrm{WO}_{3}$, and $\mathrm{TiO}_{2} / \mathrm{V}_{2} \mathrm{O}_{5}$ Heterostructure Photocatalysts}

The kinetic curves shown in Figure 5 a demonstrate degradation of probing dye at the surface of pre-exposed $\mathrm{TiO}_{2} / \mathrm{MoO}_{3}, \mathrm{TiO}_{2} / \mathrm{WO}_{3}$, and $\mathrm{TiO}_{2} / \mathrm{V}_{2} \mathrm{O}_{5}$ heterostructure photocatalysts; for comparison, the curve for bare titania is given. The efficient storage of photoproduced negative charge observed for all binary photocatalysts resulting in the induced oxidation activity imparted to their surface. This oxidation activity retains for a long time after exposure due to the formation of hydrogen bronzes of variable composition $[14,22]$ which exhibit one-electron oxidation with molecular oxygen yielding peroxo species [16].

The continuous generation of peroxo species during the course of discharging is also responsible for the long-term microbiocide effect as evident by Figure $5 b$. It is seen from Figure $5 b$ that the survival ratio for heterostructure photocatalysts even exhibited some further decreases when standing in the dark after exposure due to the buildup of the surface concentration of peroxide and then began to decline. From this point of view, the photoaccumulating heterostructure catalysts differed radically from bare $\mathrm{TiO}_{2}$, which lost the light-induced pathophysiological activity almost immediately (within one minute) after UV illumination due to short lifetimes inherent in reactive oxygen species generated at the titania surface under illumination (the lifetime of hydroxyl radicals is below a second, while the lifetime of $\mathrm{O}_{2}{ }^{-}$does not exceed $\left.50 \mathrm{~s}[23,24]\right)$. The survival ratio versus time dependencies given in Figure $5 \mathrm{~b}$ permit a conclusion that pre-exposed $\mathrm{TiO}_{2} / \mathrm{V}_{2} \mathrm{O}_{5}$ photocatalyst demonstrated higher biocide activity as compared to $\mathrm{TiO}_{2} / \mathrm{MoO}_{3}$ and $\mathrm{TiO}_{2} / \mathrm{WO}_{3}$ photocatalysts. 


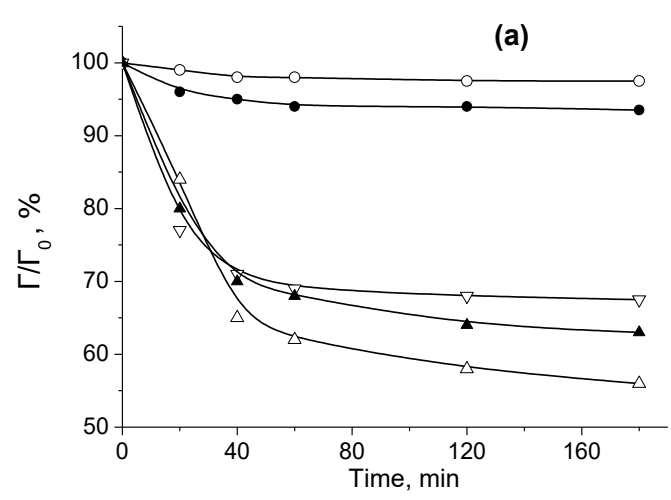

(b)

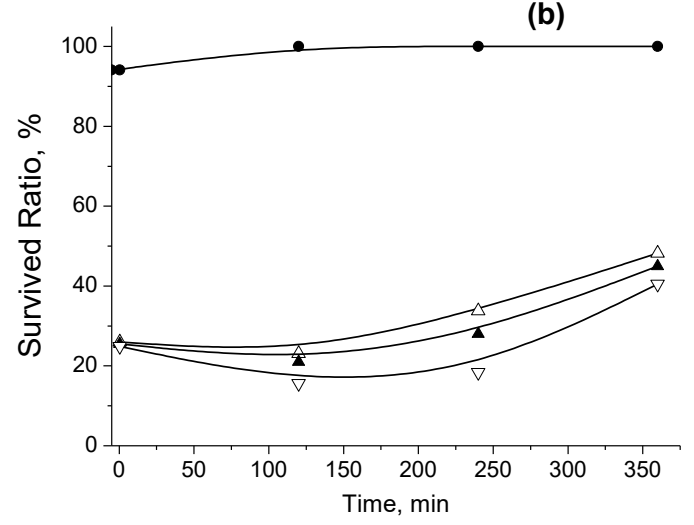

Figure 5. (a) Degradation kinetics of Rhodamine 6G at the glass substrate $(\bigcirc), \mathrm{TiO}_{2}(\bullet), \mathrm{TiO}_{2} / \mathrm{MoO}_{3}(\Delta)$, $\mathrm{TiO}_{2} / \mathrm{WO}_{3}(\boldsymbol{\Lambda})$, and $\mathrm{TiO}_{2} / \mathrm{V}_{2} \mathrm{O}_{5}(\nabla)$ photocatalysts under dark conditions after the samples were exposed to UV light for $10 \mathrm{~min}$ at $298 \mathrm{~K} . \Gamma / \Gamma_{0}$ is a ratio between measured $(\Gamma)$ and initial $\left(\Gamma_{0}\right)$ concentration of Rhodamine 6G. (b) The time dependence of the survival ratio for Escherichia coli bacteria at the surface of $\mathrm{TiO}_{2}(\bullet), \mathrm{TiO}_{2} / \mathrm{MoO}_{3}(\Delta), \mathrm{TiO}_{2} / \mathrm{WO}_{3}(\boldsymbol{\Delta})$, andTiO $\mathrm{T}_{2} / \mathrm{V}_{2} \mathrm{O}_{5}(\nabla)$ samples exposed to UV light for $10 \mathrm{~min}$ and then put in the dark for different times.

\subsection{EPR Measurements of Heterostructure Photocatalysts}

At the next step of the work, we applied an EPR technique for investigating the nature, concentration of paramagnetic centers (PCs) existing in mixed photocatalysts initially, and their change after UV irradiation. Indeed, all PCs in these systems are kinds of structural "defects" because $\mathrm{TiO}_{2}, \mathrm{MoO}_{3}, \mathrm{WO}_{3}$, and $\mathrm{V}_{2} \mathrm{O}_{5}$ contain transition metal ions, in principle, in the ground diamagnetic states such as $\mathrm{Ti}^{4+}, \mathrm{Mo}^{6+}, \mathrm{W}^{6+}$, and $\mathrm{V}^{5+}$; hence, one electron that reduced $\mathrm{Ti}^{3+}, \mathrm{Mo}^{5+}, \mathrm{W}^{5+}$, and $\mathrm{V}^{4+}$ ions can be assumed as a specific spin probe.

Spectra shown in Figure 6 demonstrate the presence of several different PCs in the initial $\mathrm{TiO}_{2} / \mathrm{MoO}_{3}$ oxide, e.g., titanium (3+) ions located in the lattice $\left(\mathrm{Ti}^{3+}{ }_{\text {lat }}\right)$ or on the surface $\left(\mathrm{Ti}^{3+}{ }_{\text {surf }}\right)$, molybdenum $\mathrm{Mo}^{5+} \mathrm{PCs}$, and nitrogen atoms usually marked as $\mathrm{N}^{\bullet}$ for stressing its paramagnetic nature. Spin Hamiltonian parameters, $g$-tensor and $A$-tensor characterizing Zeeman and hyperfine (hfi) interactions, determined from EasySpin modeling gave values represented in Table 1, which coincide in the error limits with those reported in $[16,17,25,26]$ and references therein. Earlier, it was shown by double integration of EPR spectra that no more than $1-2 \%$ of the total content of nitrogen ${ }^{14} \mathrm{~N}$ atoms are paramagnetic in these systems [26,27], while the others remain diamagnetic. It was proved that the signal from $\mathrm{N}^{\bullet}$-radical definitely appeared after high temperature treatment of oxide-hydroxide precipitate, and its source was $\mathrm{NH}_{4}{ }^{+}$residues adsorbed on the $\mathrm{TiO}_{2}$ particle surface or incorporated into the $\mathrm{TiO}_{2}$ matrix. Positions of EPR lines of other paramagnetic centers are shown in Figure 6 and agree with the literature very well. We should note that in our case, two types of $\mathrm{Mo}^{5+}$ centers were 
observed: (i) a signal $\mathrm{Mo}^{5+}$ (1) and (ii) a broad single line $\mathrm{Mo}^{5+}$ (2) with a line width $\Delta H \approx 7.0 \pm 0.6 \mathrm{mT}$, most likely caused by the presence of $\mathrm{Mo}^{5+}$ PCs in two various structural states or phases.

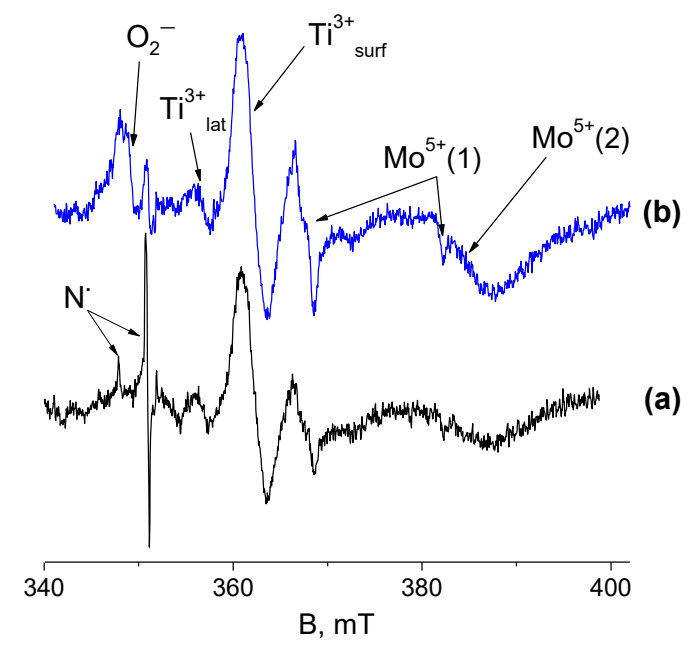

Figure 6. EPR spectra at $30 \mathrm{~K}$ of $\mathrm{TiO}_{2} / \mathrm{MoO}_{3}$ photocatalyst before (a) and after $10 \mathrm{~min}(\mathbf{b})$ of UV light illumination.

Table 1. Spin-Hamiltonian parameters calculated from EPR spectra for paramagnetic centers (PCs).

\begin{tabular}{cccc}
\hline Center & $g_{\perp}$ & $g_{\|}$ & $C$, Spin/g \\
\hline $\mathrm{Ti}^{3+}{ }_{\text {lat }}$ & 1.971 & 1.967 & $2 \times 10^{15}$ \\
$\mathrm{Ti}^{3+}{ }_{\text {surf }}$ & 1.939 & 1.929 & $(4-5) \times 10^{17}$ \\
$\mathrm{Mo}^{5+}(1)$ & $1.918,1.891^{\mathrm{a}}$ & 1.819 & $(7-9) \times 10^{17}$ \\
$\mathrm{Mo}^{5+}(2)$ & $1.804^{\mathrm{b}}$ & - & - \\
$\mathrm{W}^{5+}$ & $1.74,1.625$ & 1.568 & $<10^{15}$ \\
$\mathrm{~V}^{4+}$ & 1.980 & 1.931 & $>(2-3) \times 10^{19}$ \\
$A, \mathrm{mT}$ & 7.7 & 20.3 & $1.7 \times 10^{16}$ \\
$\mathrm{~N}^{\bullet}$ & $2.007,2.0057^{\mathrm{a}}$ & $g_{\mathrm{zz}}=2.0043$ & - \\
$<A>, \mathrm{mT}$ & $0.13,0.36^{\mathrm{c}}$ & $A_{\mathrm{zz}}=3.29$ \\
$\mathrm{O}_{2}{ }^{-}$ & $2.022,2.011^{\mathrm{d}}$ & $g_{3}=1.999$ & \\
\hline \multicolumn{5}{c}{${ }^{\mathrm{a}, \mathrm{b}}$ singlet; $^{\mathrm{c}} A_{\mathrm{xx}}, A_{\mathrm{yy}}{ }^{\mathrm{d}}{ }^{\mathrm{d}} g_{1}, g_{2}}$. \\
\end{tabular}

UV illumination of $\mathrm{TiO}_{2} / \mathrm{MoO}_{3}$ sample produced sufficient changes in the EPR spectrum (Figure 6). Since the intensity of the surface $\mathrm{Ti}^{3+}$ surf lines and both $\mathrm{Mo}^{5+} \mathrm{PC}$ increased, that of the bulk $\mathrm{Ti}^{3+}$ lat centers did not practically change, and of $\mathrm{N}^{\bullet}$ atoms decreased ca. fourfold without any changes in the line positions. Evidently, these spectral transformations directly reflect the corresponding changes in PC concentration. Note that in this system, we could also observe the appearance of the $\mathrm{O}_{2}{ }^{-}$radicals (see Figure 6). Kinetic dependences of these changes under UV irradiation are reproduced graphically in Figure 7. For better comparison, we plotted all these curves in arbitrary units.

One can see that UV illumination increased the concentrations of paramagnetic metal ions and decreased that of $\mathrm{N}^{\bullet}$-radical during ca. 50-60 min of treatment, and afterwards they stayed constant reflecting stationary rates of the creation and decay of these PCs. All changes were impressive: from four- to fivefold (Figure 7). It is also obvious that the rate of photogeneration of all these metal PCs at first $60 \mathrm{~min}$ of irradiation was practically equal, and this allows the assumption that all observed reduction processes were correlated and not independent. 


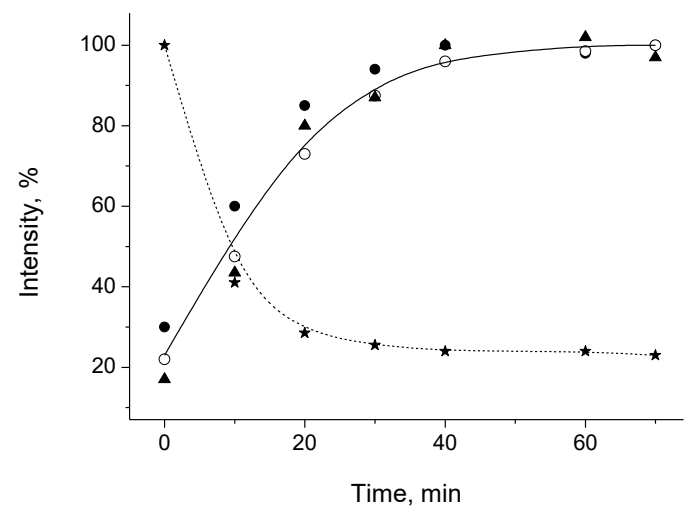

Figure 7. Dependences of EPR signal intensity as a function of UV illumination time for $\mathrm{Ti}^{3+}$ surf $(\mathbf{\Lambda})$, $\mathrm{N}^{\bullet}$ radical $($ star $), \mathrm{Mo}^{5+}(\bigcirc)$, and $\mathrm{V}^{4+}(\bullet)$ PCs.

In the dark conditions after switching off illumination, created paramagnetic centers were re-oxidized by air dioxygen and by electron transfer reactions between reduced PCs according to their red-ox potentials. These processes were much slower (over 30-40 h, see Figure 8) due to complex character of the electron transfer in such nanosized heterojunction systems $[14-18,25]$. Note that (i) at the first $10 \mathrm{~h}$ in the dark, the decay was exponential, and later it became practically linear fitted; (ii) the rate of the decay processes varied on the metal nature: $\mathrm{Ti}^{3+}$ surf concentration changed faster than that of $\mathrm{V}^{4+}$; (iii) concentration of $\mathrm{N}^{\bullet}$ radicals increased linearly during all $40 \mathrm{~h}$ (Figure 8).

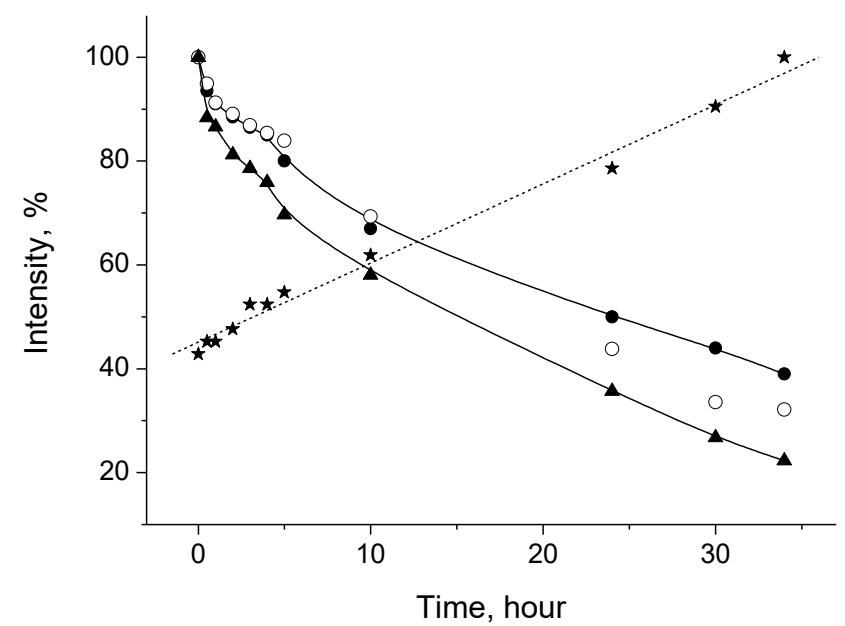

Figure 8. Dependences of EPR signal intensity as a function of time after switching off UV light for $\mathrm{Ti}^{3+}$ surf $(\boldsymbol{\Lambda}), \mathrm{N}^{\bullet}$ radical $($ star $), \mathrm{Mo}^{5+}(\bigcirc)$, and $\mathrm{V}^{4+}(\bullet)$ PCs.

UV irradiation of $\mathrm{TiO}_{2} / \mathrm{WO}_{3}$ also produced noticeable changes (Figure 9): initial EPR signal recorded in dark conditions $(g \approx 1.63$ and $\Delta H \approx 23.0 \mathrm{mT})$ transformed to a new spectrum with parameters listed in Table 1, which correlate with $g$-values published in [28-31]. The observed three-axes anisotropy is usual for $\mathrm{W}^{5+} \mathrm{PCs}$. Unfortunately, we could not quantitatively characterize kinetics under illumination and in the dark afterwards due to very noisy EPR spectra recording (Figure 9). 


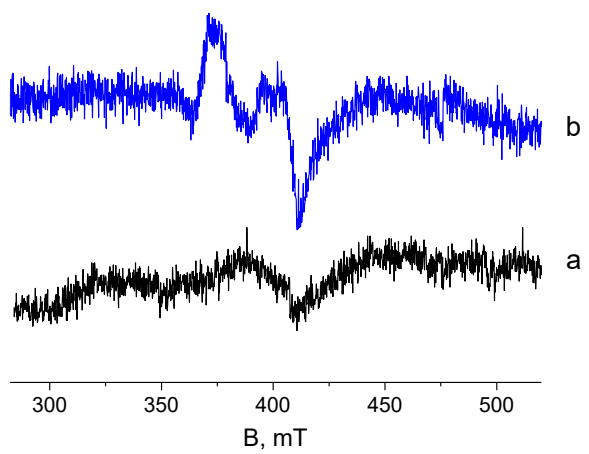

Figure 9. EPR spectra of $\mathrm{TiO}_{2} / \mathrm{WO}_{3}$ photocatalyst before (a) and after $10 \mathrm{~min}(\mathbf{b})$ of UV light illumination.

Figure 10 represents changes in EPR spectra after 10 min of UV illumination of $\mathrm{TiO}_{2} / \mathrm{V}_{2} \mathrm{O}_{5}$ photocatalyst, which led to an approximately twofold increase in the spectrum intensity. The kinetics of $\mathrm{V}^{4+}$ signal grove and its decay in the dark conditions are shown in Figures 7 and 8. We would stress that the EPR signal intensity of $\mathrm{V}^{4+}$ PCs in mixed oxides containing vanadium pentoxide as one of the components is so high that spectra of $\mathrm{Ti}^{3+}$ or $\mathrm{Mo}^{5+}$ paramagnetic species cannot be observed due to their much lower amplitude as well as the high oxidative properties of $\mathrm{V}^{5+}$ ions in $\mathrm{V}_{2} \mathrm{O}_{5}$.

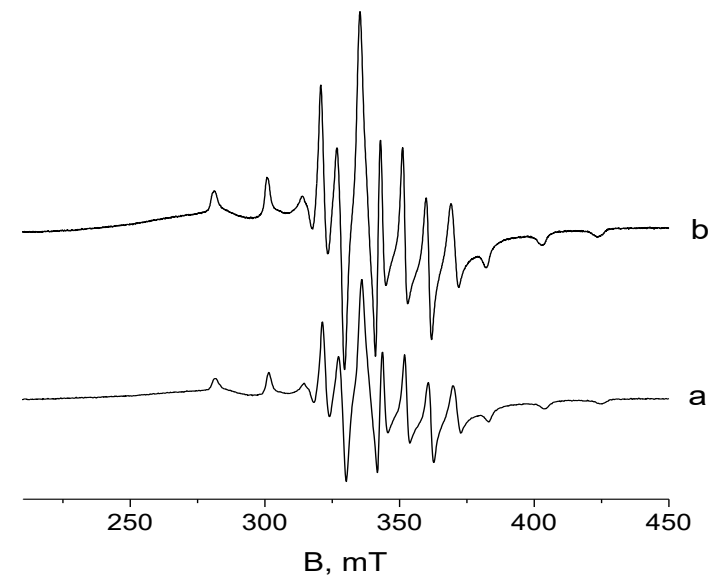

Figure 10. EPR spectra of $\mathrm{TiO}_{2} / \mathrm{V}_{2} \mathrm{O}_{5}$ photocatalyst before (a) and after $10 \mathrm{~min}$ (b) of UV light illumination.

It has been shown recently that the position of energy levels corresponding to the charge accepting states in the bandgap of $\mathrm{TiO}_{2}, \mathrm{MoO}_{3}$, and $\mathrm{V}_{2} \mathrm{O}_{5}\left(\mathrm{Mo}^{6+} / \mathrm{Mo}^{5+}, \mathrm{V}^{5+} / \mathrm{V}^{4+}, \mathrm{Ti}^{4+} / \mathrm{Ti}^{3+}\right)$ can be determined from EPR measurements under in situ illumination [16]. The energies of these levels measured against the valence band of corresponding semiconductors are collected in Table 2. It should be noted that $\mathrm{Ti}^{4+} / \mathrm{Ti}^{3+}$ states involved into the charge exchange correspond to the surface states, whereas the population of lattice $\mathrm{Ti}^{4+} / \mathrm{Ti}^{3+}$ states is not modulated under illumination [16].

Table 2. Energy position of levels involved in the charge storage in $\mathrm{TiO}_{2} / \mathrm{MoO}_{3}, \mathrm{TiO}_{2} / \mathrm{WO}_{3}$, and $\mathrm{TiO}_{2} / \mathrm{V}_{2} \mathrm{O}_{5}$ photocatalysts (energy is measured against the valence band of semiconductor).

\begin{tabular}{cc}
\hline Charge Accepting States & Energy, eV \\
\hline $\mathrm{Ti}^{4+} / \mathrm{Ti}^{3+*}$ & $2.9^{*}$ \\
$\mathrm{Mo}^{6+} / \mathrm{Mo}^{5+}$ & $2.7^{*}$ \\
$\mathrm{~W}^{6+} / \mathrm{W}^{5+}$ & $2.4^{* *}$ \\
$\mathrm{~V}^{5+} / \mathrm{V}^{4+}$ & $2.2^{*}$
\end{tabular}

* The value was obtained from the EPR measurements [16]; ** the value was obtained from the X-ray photoelectron spectra [32]. 
Due to the low signal-to-noise ratio exhibited by $\mathrm{TiO}_{2} / \mathrm{WO}_{3}$ that did not allow the determination of reliable energy value of $\mathrm{W}^{6+} / \mathrm{W}^{5+}$ states from EPR spectra, this energy was estimated from the X-ray photoelectron spectra for tungsten oxide bronzes [32]. Using the photocurrent onset potential values, $E_{\text {on }}$, given in Table 3 as the rough estimation of the energy position of the bottom of the conduction band of highly doped $\mathrm{TiO}_{2}, \mathrm{MoO}_{3}, \mathrm{WO}_{3}$, and $\mathrm{V}_{2} \mathrm{O}_{5}$, one can obtain the detailed energy diagram of the energy storage photocatalysts under consideration (Figure 11).

Table 3. The band gap energies $\left(E_{\mathrm{g}}\right)$ and the photocurrent onset potentials $\left(E_{\mathrm{on}}\right)$ for oxides used for preparation of heterostructured photocatalysts.

\begin{tabular}{ccc}
\hline Oxide & $\boldsymbol{E}_{\mathbf{g}}{ }^{*}, \mathbf{e V}$ & $\boldsymbol{E}_{\mathbf{o n}}, \mathbf{V}$ \\
\hline $\mathrm{TiO}_{2}$ & 3.50 & -0.4 \\
$\mathrm{MoO}_{3}$ & 3.01 & -0.2 \\
$\mathrm{WO}_{3}$ & 2.75 & -0.1 \\
$\mathrm{~V}_{2} \mathrm{O}_{5}$ & 2.45 & 0.0 \\
\hline
\end{tabular}

* $E_{\mathrm{g}}$ values were obtained from the optical absorption spectra.

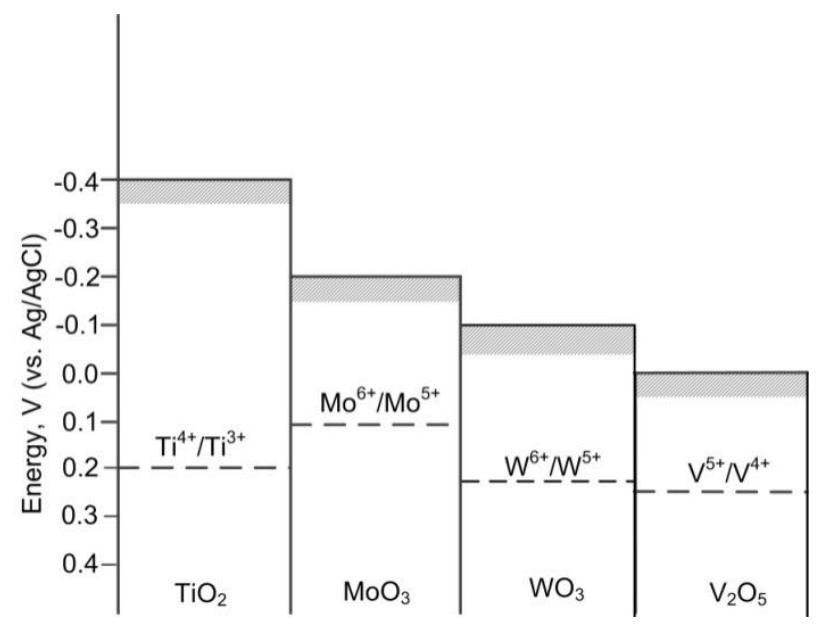

Figure 11. Schematic energy diagram of $\mathrm{TiO}_{2} / \mathrm{MoO}_{3}, \mathrm{TiO}_{2} / \mathrm{WO}_{3}$, and $\mathrm{TiO}_{2} / \mathrm{V}_{2} \mathrm{O}_{5}$ photocatalysts.

The EPR measurements strongly show that in the case of $\mathrm{TiO}_{2} / \mathrm{MoO}_{3}$ photocatalyst, there were two mechanisms of accumulation of negative charge photoproduced in $\mathrm{TiO}_{2}$ : (i) injection of electrons into $\mathrm{MoO}_{3}$ followed by redox transformations of oxide accompanied by the formation of $\mathrm{Mo}(\mathrm{V})$ centers readily detectable in EPR spectra; (ii) "indirect" filling of $\mathrm{Ti}^{4+} / \mathrm{Ti}^{3+}$ surface states via electron transfer from $\mathrm{Mo}^{6+} / \mathrm{Mo}^{5+}$ states which lie at higher energies. The latter process in the case of bare $\mathrm{TiO}_{2}$ appeared to be completely hindered since the rate constant of electron trapping at these states was much lower as compared to the rate constant of surface recombination. In the $\mathrm{TiO}_{2} / \mathrm{MoO}_{3}$ heterostructure photocatalyst, $\mathrm{Ti}^{4+} / \mathrm{Ti}^{3+}$ states were in equilibrium with the $\mathrm{Mo}^{6+} / \mathrm{Mo}^{5+}$ states, and their filling was not compete with recombination. By contrast, it is seen from the energy diagram given in Figure 11 that both $\mathrm{W}^{6+} / \mathrm{W}^{5+}$ and $\mathrm{V}^{5+} / \mathrm{V}^{4+}$ states lay below $\mathrm{Ti}^{4+} / \mathrm{Ti}^{3+}$ states and thus did not contribute to their filling. As a result, in the case of $\mathrm{TiO}_{2} / \mathrm{WO}_{3}$ and $\mathrm{TiO}_{2} / \mathrm{V}_{2} \mathrm{O}_{5}$ photocatalysts, the redox transformations in $\mathrm{WO}_{3}$ and $\mathrm{V}_{2} \mathrm{O}_{5}$ appeared to be the only mechanism responsible for charge storage.

The charged $\mathrm{Ti}^{4+} / \mathrm{Ti}^{3+}$ states at the surface of titania nanoparticles can be readily oxidized with oxygen from the air yielding peroxo species, which resulted in a high initial rate of probing dye degradation at the pre-exposed photocatalyst (Figure 1). However, due to rapid consumption of the charges accumulated at $\mathrm{Ti}^{4+} / \mathrm{Ti}^{3+}$ states, their contribution to the long-term pathophysiological activity was marginal. As a result, the photoinduced biocide activity of $\mathrm{TiO}_{2} / \mathrm{MoO}_{3}$ photocatalyst (as evident by Figure 2) appeared to be less than the photoinduced biocide activity of $\mathrm{TiO}_{2} / \mathrm{WO}_{3}$ and $\mathrm{TiO}_{2} / \mathrm{V}_{2} \mathrm{O}_{5}$ photocatalysts accumulating photoinduced charges solely in the form of hydrogen 
bronzes (and, therefore, demonstrating a lower initial rate of probing dye degradation-Figure 1). The oxidation of the hydrogen bronzes occurred slowly being governed by the diffusion of redox centers from the bulk of nanocrystals of redox-active oxides to their surface that ensure continuous production of peroxide (and guarantees high antimicrobial activity level) during a long period of time. The energy diagram given in Figure 11 also shows that combining nanoparticles of different oxides in the photocayalyst film, it is possible to realize cascade effects that ensure efficient separation and accumulation of photoproduced charges.

The EPR measurements thus provide evidence that in the case of heterostructure photocatalysts with mosaic surfaces (i.e., comprising photogenerating and redox-active components), the exposure to the actinic light results in the generation of charge-trapping reaction centers of several types exhibiting different oxidation activity and long-term stability. As a result, these centers make different contributions in the induced pathophysiological behavior of energy storage photocatalysts.

\section{Materials and Methods}

The thin-film photocatalysts were prepared using aqueous dispersions of $\mathrm{TiO}_{2}, \mathrm{MoO}_{3}, \mathrm{WO}_{3}$, and $\mathrm{V}_{2} \mathrm{O}_{5}$ (Sigma-Aldrich, St. Louis, MO, USA). The aqueous sol of titania was prepared by adding $12.5 \% \mathrm{NH}_{4} \mathrm{OH}$ dropwise to $2.5 \mathrm{M} \mathrm{TiCl}_{4}+0.65 \mathrm{M} \mathrm{HCl}$ aqueous solution (Sigma-Aldrich, St. Louis, $\mathrm{MO}$, USA) cooled to $0{ }^{\circ} \mathrm{C}$ under vigorous stirring until $\mathrm{pH} 5$ was reached. The obtained precipitate after thorough washing with distilled water was dispersed by ultrasonic treatment. The size of the obtained $\mathrm{TiO}_{2}$ particles (anatase) was of ca. $4 \mathrm{~nm}$. The aqueous suspensions of $\mathrm{MoO}_{3}$ and $\mathrm{V}_{2} \mathrm{O}_{5}$ were synthesized via the thermally-induced polycondensation of corresponding oxo-compounds in aqueous medium. The oxo-acids used as precursors were prepared by acidification of aqueous solutions of sodium molybdate and sodium vanadate on a resin. The two-step synthetic route yielding oxide particles of submicron size [21] was used. At the first step, $0.5 \mathrm{M}$ solutions of molybdic, vanadic, and tungstic acids were heated at $100{ }^{\circ} \mathrm{C}$ for $4 \mathrm{~min}$; the resultant solution was diluted 1:5 to stop further nucleation as well as to provide dispersion of grown oxide particles and then incubated for $4 \mathrm{~h}$ at 100 ${ }^{\circ} \mathrm{C}$ (the solution volume was maintained constant).

The X-ray diffraction analysis of the samples was performed with the use of a PANalytical Empyrean difractometer with $\mathrm{Cu} \mathrm{K} \mathrm{K}_{\alpha}$ radiation. The morphological investigations emploed SEM (LEO 1420, KARL ZEISS, Germany) and AFM microscope (NT-206, MICROTESTMACHINES, Gomel, Belaru).

As the UV light source in the photocatalytic measurements, the high-pressure mercury lamp Philips HPK $125 \mathrm{~W}$ was used. The intensity of the incident light was of ca. $10 \mathrm{~mW} / \mathrm{cm}^{2}$.

The photoinduced oxidation activity of $\mathrm{TiO}_{2} / \mathrm{MoO}_{3}$ and $\mathrm{TiO}_{2} / \mathrm{V}_{2} \mathrm{O}_{5}$ systems was evaluated using the reaction of degradation of probing dye (Rhodamine 6G) deposited onto the photocatalyst surface which was preliminary exposed to UV light for $10 \mathrm{~min}$. Rhodamine 6G was applied onto the photocatalyst surface at different times after exposure in an amount of ca. $2 \times 10^{-8} \mathrm{~mol} / \mathrm{cm}^{2}$, and a diffuse reflectance, $R$, at $530 \mathrm{~nm}$ that corresponded to the absorption of the dye in the adsorbed state was measured. The value proportional to the surface dye concentration $(\Gamma)$ was calculated from the reflectance data using the Kubelka-Munk function [33]:

$$
\Gamma \sim(1-R)^{2} / 2 R
$$

The photocurrent onset potentials for the $\mathrm{TiO}_{2}, \mathrm{MoO}_{3}, \mathrm{WO}_{3}$, and $\mathrm{V}_{2} \mathrm{O}_{5}$ thin films deposited onto ITO were obtained from photocurrent versus potential dependencies measured in $0.25 \mathrm{Na}_{2} \mathrm{SO}_{4}+$ $0.1 \mathrm{CH}_{3} \mathrm{COONa}$ electrolyte using the Autolab PGStat 204 potentiostat (Metrohm Autolab, Utrecht, The Netherlands). All potentials are given against saturated $\mathrm{Ag} / \mathrm{AgCl}$ reference electrode.

The photoinduced pathphysiological activity of photoaccumulating catalyst was investigated using Escherichia coli ATCC 8739 bacteria. For this purpose, the samples of thin-film photocatalysts at glass substrates $(4 \times 4 \mathrm{~cm})$ pasted with the agar at the bottom of Petri dish were exposed to UV light for $10 \mathrm{~min}$ and left in the dark for different times to evaluate the deactivation kinetics. Then, 
$5 \mathrm{~mL}$ of suspension of microorganisms in $0.5 \% \mathrm{LB}$ agar medium was poured into the dish. Plates were then incubated for $48 \mathrm{~h}$ at $37^{\circ} \mathrm{C}$, and the number of arising colonies, $N$, was calculated. In the control experiments, the photocatalyst-free glass substrates were used. To evaluate the biocide activity of the pre-illuminated photocataylys, the survived ratio, $S=\left(N / N_{0}\right) \cdot 100 \%$, was used $\left(N_{0}\right.$ is the number of colony-forming units in the case of the nonexposed photocatalyst used as the control sample). The respective data were the average values obtained from the triplicate runs. The standard deviations of these replicate experiments were within $14 \%$.

The EPR spectra were recorded with a EPR spectrometer (ELEXSYS-E500, X-band, the sensitivity up to $10^{10} \mathrm{spin} / \mathrm{G}$, Bruker, Karlsruhe, Germany). For investigation of photogenerated paramagnetic centers (PCs), the samples were illuminated directly in the cavity of the spectrometer with the use of a $50 \mathrm{~W}$ high pressure mercury lamp. The concentration of $\mathrm{PCs}$ was evaluated using $\mathrm{CuCl}_{2} \cdot 2 \mathrm{H}_{2} \mathrm{O}$ monocrystal with the known number of spins as the standard. The EPR spectra simulation permitting the determination of $g$-factor values of paramagnetic centers was carried out with the use of EasySpin MATLAB toolbox (Comprehensive Software Package for Spectral Simulation and Analysis in EPR, Stoll, S.; Schweiger, A., Physical Chemistry Laboratory, ETH Hönggerberg, Zürich, Switzerland, 2006) [34].

\section{Conclusions}

The obtained results provide evidence that the structure of energy levels involved in the separation of photoproduced charges in the case of $\mathrm{TiO}_{2} / \mathrm{MoO}_{3}$ photocatalyst creates favorable conditions for filling the energy states of $\mathrm{TiO}_{2}$ (the latter process is not observed for bare $\mathrm{TiO}_{2}$ ). As a result, the accumulation of photoinduced charges occurs in two forms: (i) filled electron traps corresponding to $\mathrm{Ti}^{4+} / \mathrm{Ti}^{3+}$ levels and (ii) $\mathrm{Mo}^{5+}$ centers produced as the result of electron trapping by $\mathrm{MoO}_{3}$, both forms contributing to the photoinduced biocide activity of the heterostructure photocatalyst. This effect of "indirect" filling of $\mathrm{Ti}^{4+} / \mathrm{Ti}^{3+}$ surface states resulted from the cascade effect is not observed for $\mathrm{TiO}_{2} / \mathrm{WO}_{3}$ and $\mathrm{TiO}_{2} / \mathrm{V}_{2} \mathrm{O}_{5}$ heterostructures due to deeper lying $\mathrm{W}^{+6} / \mathrm{W}^{+5}$ and $\mathrm{V}^{5+} / \mathrm{V}^{4+}$ levels involved in the electron trapping. In the case of $\mathrm{TiO}_{2} / \mathrm{WO}_{3}$ and $\mathrm{TiO}_{2} / \mathrm{V}_{2} \mathrm{O}_{5}$ photocatalysts, the electron trapping is irreversible and occurs at the bulk $\mathrm{W}^{+6} / \mathrm{W}^{+5}$ and $\mathrm{V}^{5+} / \mathrm{V}^{4+}$ states. This permits the conclusion that the exposure of energy storage heterostructure photocatalysts with mosaic surfaces (i.e., comprising photogenerating and redox-active components) to actinic light can result in the generation of different types of charge-trapping centers capable of interacting with molecular oxygen yielding peroxo species; these centers differ as to their long-term stability and contribution to the induced pathophysiological behavior.

Author Contributions: Conceptualization, A.I.K. and D.W.B.; methodology, T.V.S.; validation, E.A.K., T.V.S., and A.I.K.; formal analysis, D.V.S.; investigation, T.V.S., E.A.K.; data curation, D.V.S.; writing一original draft preparation, A.I.K.; writing-review and editing, D.W.B., A.I.K.; visualization, D.V.S., E.A.K.; supervision, D.W.B. All authors have read and agreed to the published version of the manuscript.

Funding: A.I.K. and E.A.K. are thankful to the Russian Foundation of Basic Research for financial support (Grant No. 18-53-00020-Bel-a). T.V.S and D.V.S. acknowledge the support from the Belarusian Republican Foundation for Fundamental Research (Grant Kh19MS-017).

Acknowledgments: The EPR measurements were performed using the facilities of the Collective Use Center at the Moscow State University.

Conflicts of Interest: The authors declare no conflict of interest.

\section{References}

1. Ge, M.; Li, Q.; Cao, C.; Huang, J.; Li, S.; Zhang, S.; Chen, Z.; Zhang, K.; Al-Deyab, S.S.; Lai, Y.; et al. One-dimensional $\mathrm{TiO}_{2}$ nanotube photocatalysts for solar water splitting. Adv. Sci. 2017, 4, 1-31.

2. Hoffmann, M.R.; Martin, S.T.; Choi, W.; Bahnemann, D.W. Environmental applications of semiconductor photocatalysis. Chem. Rev. 1995, 95, 69-96. [CrossRef]

3. Hagfeldt, A.; Graetzel, M. Light-Induced redox reactions in nanocrystalline systems. Chem. Rev. 1995, 95, 49-68. [CrossRef] 
4. Ibhadon, A.O.; Fitzpatrick, P. Heterogeneous photocatalysis: Recent advances and applications. Catalysts 2013, 3, 189-218. [CrossRef]

5. Bahnemann, D. Photocatalytic water treatment: Solar energy applications. Solar Energy 2004, 77, 445-459. [CrossRef]

6. Chen, X.; Mao, S. Titanium dioxide nanomaterials: Synthesis, properties, modifications, and applications. Chem. Rev. 2007, 107, 2891-2959. [CrossRef]

7. Zhang, H.; Chen, G.; Bahnemann, D. Photoelectrocatalytic materials for environmental applications. J. Mat. Chem. 2009, 19, 5089-5121. [CrossRef]

8. Chen, W.F.; Koshy, P.; Huang, Y.; Adabifiroozjaei, E.; Yao, Y.; Sorrell, C.C. Effects of Precipitation, Liquid. Formation, and Intervalence Charge Transfer on the Properties and Photocatalytic Performance of Cobalt-. or Vanadium-Doped $\mathrm{TiO}_{2}$ Thin Films. Int. J. Hydrog. Energy 2016, 41, 19025-19056. [CrossRef]

9. Schneider, J.; Matsuoka, M.; Takeuchi, M.; Zhang, J.; Horiuchi, Y.; Anpo, M.; Bahnemann, D.W. Understanding $\mathrm{TiO}_{2}$ photocatalysis: Mechanisms and materials. Chem. Rev. 2014, 114, 9919-9986. [CrossRef]

10. Tatsuma, T.; Takeda, S.; Saitoh, S.; Ohko, Y.; Fujishima, A. Bactericidal effect of an energy storage $\mathrm{TiO}_{2}-\mathrm{WO}_{3}$ photocatalyst in dark. Electrochem. Comm. 2003, 5, 793-796. [CrossRef]

11. Takahashi, Y.; Ngaotrakanwiwat, P.; Tatsuma, T. Energy storage $\mathrm{TiO}_{2}-\mathrm{MoO}_{3}$ photocatalysts. Electrochim. Acta 2004, 49, 2025-2029. [CrossRef]

12. Yang, F.; Takahashi, Y.; Sakai, N.; Tatsuma, T. Visible light driven photocatalysts with oxidative energy storage abilities. J. Mat. Chem. 2011, 21, 2288-2293. [CrossRef]

13. Ngaotrakanwiwat, P.; Saitoh, S.; Ohko, Y.; Tatsuma, T.; Fujishima, A. $\mathrm{TiO}_{2}$-phosphotungstic acid photocatalysis systems with an energy storage ability. J. Electrochem. Soc. 2003, 150, A1405-A1407. [CrossRef]

14. Sviridova, T.V.; Sadovskaya, L.Y.; Shchukina, E.M.; Logvinovich, A.S.; Shchukin, D.G.; Sviridov, D.V. Nanoengineered Thin-Film $\mathrm{TiO}_{2} / \mathrm{h}-\mathrm{MoO}_{3}$ Photocatalysts Capable to Accumulate Photoinduced Charge. J. Photochem. Photobiol. A 2016, 327, 44-50. [CrossRef]

15. Sviridova, T.V.; Antonova, A.A.; Kokorin, A.I.; Degtyarev, E.N.; Sviridov, D.V. Thermally Induced Transformations in Nanostructured Molybdenum-Vanadium Oxides Synthesized by a Solvothermal Method. Russ. J. Phys. Chem. B 2015, 9, 36-42. [CrossRef]

16. Konstantinova, E.A.; Kokorin, A.I.; Minnekhanov, A.A.; Sviridova, T.V.; Sviridov, D.V. EPR Study of Photoexcited Charge Carrier Behavior in $\mathrm{TiO}_{2} / \mathrm{MoO}_{3}$ and $\mathrm{TiO}_{2} / \mathrm{MoO}_{3}: \mathrm{V}_{2} \mathrm{O}_{5}$ Photocatalysts. Catal. Lett. 2019, 149, 2256-2267. [CrossRef]

17. Sviridova, T.V.; Sadovskaya, L.Y.; Konstantinova, E.A.; Belyasova, N.A.; Kokorin, A.I.; Sviridov, D.V. Photoaccumulating $\mathrm{TiO}_{2}-\mathrm{MoO}_{3}, \mathrm{TiO}_{2}-\mathrm{V}_{2} \mathrm{O}_{5}$, and $\mathrm{TiO}_{2}-\mathrm{WO}_{3}$ Heterostructures for Self-Sterilizing Systems with the Prolonged Bactericidal Activity. Catal. Lett. 2019, 149, 1147-1153. [CrossRef]

18. Kokorin, A.I.; Sviridova, T.V.; Kolbanev, I.V.; Sadovskaya, L.Y.; Degtyarev, E.N.; Vorobyeva, G.A.; Streletskii, A.N.; Sviridov, D.V. Structure and Photocatalytic Properties of $\mathrm{TiO}_{2} / \mathrm{MoO}_{3}$ and $\mathrm{TiO}_{2} / \mathrm{V}_{2} \mathrm{O}_{5}$ Nanocomposites Obtained by Mechanochemical Activation. Russ. J. Phys. Chem. B 2018, 12, 330-335. [CrossRef]

19. Choi, W.; Termin, A.; Hoffmann, M.R. The Role of Metal Ion Dopants in Quantum-Sized $\mathrm{TiO}_{2}$ : Correlation between Photoreactivity and Charge Carrier Recombination Dynamics. J. Phys. Chem. 1994, 98, 13669-13679. [CrossRef]

20. Polliotto, V.; Livraghi, S.; Giamello, E. Electron magnetic resonance as a tool to monitor charge separation and reactivity in photocatalytic materials. Res. Chem. Intermed. 2018, 44, 3905-3921. [CrossRef]

21. Sviridova, T.V.; Stepanova, L.I.; Sviridov, D.V. Molybdenum: Characteristics, Production and Applications in Nanoand Microcrystals of Molybdenum Trioxide and Metal-Matrix Composites on Their Basis; Ortiz, M., Herrera, T., Eds.; Nova Science Publishers: New York, NY, USA, 2012; p. 147.

22. Sviridova, T.V.; Stepanova, L.I.; Sviridov, D.V. Electrochemical synthesis of $\mathrm{Ni}-\mathrm{MoO}_{3}$ composite films: Redox-mediated mechanism of electrochemical growth of metal-matrix composite. J. Sol. St. Electrochem. 2012, 16, 3799-3803. [CrossRef]

23. Ishibashi, K.; Fujishima, A.; Watanabe, T.; Hashimoto, K. Quantum yields of active oxidative species formed on $\mathrm{TiO}_{2}$ photocatalyst. J. Photochem. Photobiol. A 2000, 134, 139-142. [CrossRef]

24. Ishibashi, K.; Fujishima, A.; Watanabe, T.; Hashimoto, K. Generation and deactivation processes of superoxide formed on $\mathrm{TiO}_{2}$ film illuminated byvery weak UV light in air or water. J. Phys. Chem. B 2000, 104, 4934-4938. [CrossRef] 
25. Konstantinova, E.A.; Minnekhanov, A.A.; Kokorin, A.I.; Sviridova, T.V.; Sviridov, D.V. Determination of the Energy Levels of Paramagnetic Centers in the Band Gap of Nanostructured Oxide Semiconductors Using EPR Spectroscopy. J. Phys. Chem. C 2018, 122, 10248-10254. [CrossRef]

26. Konstantinova, E.A.; Kokorin, A.I.; Lips, K.; Sakthivel, S.; Kisch, H. EPR study of illumination effect on properties of paramagnetic centers in nitrogen-doped $\mathrm{TiO}_{2}$, active in visible light photocatalysis. Appl. Magn. Reson. 2009, 35, 421-427. [CrossRef]

27. Sviridova, T.V.; Sadovskaya, L.Y.; Kokorin, A.I.; Konstantinova, E.A.; Agabekov, V.E.; Sviridov, D.V. Photoaccumulating Film Systems Based on $\mathrm{TiO}_{2} / \mathrm{MoO}_{3}$ and $\mathrm{TiO}_{2} / \mathrm{MoO}_{3}: \mathrm{V}_{2} \mathrm{O}_{5}$ Nanoheterostructures. Russ. J. Phys. Chem. B 2017, 11, 348-353. [CrossRef]

28. Kokorin, A.I. Electron Spin Resonance of Nanostructured Oxide Semiconductors in Chemical Physics of Nanostructured Semiconductors; Kokorin, A.I., Bahnemann, D.W., Eds.; VSP-Brill Academic Publishers: Utrecht, The Netherlands; Boston, MA, USA, 2003; p. 203.

29. Occhiuzzi, M.; Cordischi, D.; Gazzoli, D.; Valigi, M.; Heydorn, P.C. $\mathrm{WO}_{\mathrm{x}} / \mathrm{ZrO}_{2}$ catalysts: Part 4. Redox properties as investigated by redox cycles, XPS and EPR. Appl. Catal. A 2004, 269, 169-177. [CrossRef]

30. Folli, A.; Blohb, J.Z.; Macphee, D.E. Band structure and charge carrier dynamics in (W,N)-codoped $\mathrm{TiO}_{2}$ resolved by electrochemical impedance spectroscopy combined with UV-vis and EPR spectroscopies. J. Electroanalyt. Chem. 2016, 780, 367-372. [CrossRef]

31. Gazzinelli, R.; Schirmer, O.F. Light induced $\mathrm{W}^{5+}$ ESR in $\mathrm{WO}_{3}$. J. Phys. C Sol. St. Phys. 1977, 10, L145-L149. [CrossRef]

32. Hashimoto, S.; Matsuoka, H. Mechanism of electrochromism for amorphous $\mathrm{WO}_{3}$ thin films. J. Appl. Phys. 1991, 69, 933-937. [CrossRef]

33. Wedland, W.; Hecht, H. Reflectance Spectroscopy; Interscience Publishers: New York, NY, USA, 1966.

34. Stoll, S.; Schweiger, A. EasySpin, a Comprehensive Software Package for Spectral Simulation and Analysis in EPR. J. Magn. Reson. 2006, 178, 42-55. [CrossRef]

(C) 2020 by the authors. Licensee MDPI, Basel, Switzerland. This article is an open access article distributed under the terms and conditions of the Creative Commons Attribution (CC BY) license (http://creativecommons.org/licenses/by/4.0/). 